(C) 2017, Elsevier. Licensed under the Creative Commons Attribution-NonCommercialNoDerivatives 4.0 International

http://creativecommons.org/licenses/by-nc-nd/4.0/

\title{
Effect of microwave irradiation on the viscosity of crude oil: a view at the molecular level
}

Hui Shang ${ }^{1, *}$, Yude Yue ${ }^{1}$, Jie Zhang ${ }^{1}$, Jiawei Wang ${ }^{2}$, Quan Shi ${ }^{l}$, Wenhui Zhang ${ }^{1}$, Lu Liu ${ }^{l}$, Sainab Omar ${ }^{2}$

${ }^{1}$ State Key Laboratory of Heavy Oil Processing, China University of Petroleum (Beijing), Changping District, Beijing, 102249, P.R. China

${ }^{2}$ European Bioenergy Research Institute, Aston University, Aston Triangle, Birmingham, B4 7ET, UK

\begin{abstract}
The increase in global energy demand and decrease in easily extractable light crude oil has generated a growing interest in heavy oil exploitation. However, the high viscosity of heavy oil leads to exploitation, transportation and refining challenges. In this context, microwave irradiation of crude oil samples from Sudan, China (Liaohe) and Venezuela were carried out to investigate the mechanisms of viscosity reduction. Saturate, aromatic, resin, and asphaltene (SARA) analysis of the crude oils was conducted according to the American Society Test and Materials standard, ASTM D4124-09. The SARA fractionation results demonstrated that microwave irradiation may affect the structure of resin/asphaltene micelles, thus leading to a change in the viscosity of the crude oil. The crude oils were further examined using the combined analytical techniques of electrospray ionization and Fourier transform ion cyclotron resonance mass spectrometry (ESI FT-ICR MS). The results from ESI FT-ICR MS analysis demonstrated that microwave irradiation of crude oil with a high proportion of $\mathrm{O}_{2}$ compounds leads to polymerization, and ultimately an increase in the viscosity of the crude oil after microwave treatment. In other cases, cracking might occur due to the microwave heating.
\end{abstract}

\section{Key words: Microwave irradiation; Viscosity; Composition; Crude oil; Heavy oil}

\section{Introduction}

In recent years, factors such as increasing global energy demand, and rapid economic development of countries such as China and India, has led to the high consumption of petroleum products. To meet this demand, increased attention is focused on unconventional resources such as heavy oil and oil sands due to their enormous reserves. Heavy oil is defined as crude oil with a relative density higher than 0.92 or if the oil viscosity is higher than $100 \mathrm{mPa} \cdot \mathrm{s}$ at the reservoir temperature. Heavy oil currently occupies at least half of the world's recoverable oil resources [1,2], and is mainly distributed in Venezuela,

\footnotetext{
* Corresponding author, Tel.: 0086-10-89731120; Fax: 0086-10-69724721. Email: shanghlj@msn.com
} 
Canada, Russia, America and China [2,3]. However, drilling and transportation of heavy oils is a challenging task due to its high viscosity and high density, which can lead to flow and processing problems.

The main methods to reduce the viscosity of heavy oils include heating, dilution, emulsification, using chemical agents, catalytic reforming and microwave heating. Conventional heating is the predominant technique used for reducing viscosity due to crude oils high sensitivity to temperature. However, this is an energy intensive method, which necessitates the combustion of $1 \%$ of transported crude oil to meet the energy requirements. Moreover, heavy oil viscosity reduction by the conventional heating method is a reversible process, thus, the viscosity level approaches the original value once the temperature decreases. Consequently, several heating equipments must be installed along the transport pipeline to maintain the viscosity at an acceptable level. As a result, the capital and operational costs of the conventional heating method is significantly high especially over long distances of pipelines [2].

Another widely used method for viscosity reduction is the dilution of heavy oil by mixing with lighter liquid hydrocarbons [1,4,5]. This is the simplest method, and it is more efficient for low wax content oil. For this method there must be a light oil resource and the crude oil needs to be dewatered before mixing. However, the physical properties of the crude oil will change if mixed with other oils. Another important drawback is that the transport capacity significantly increases. It is also important to highlight that the addition of light paraffin could lead to asphaltene precipitation, this may cause problems during the oil production [6,7]. Other viscosity reduction techniques, such as emulsification, chemical dosage, ultrasonic treatment and magnetic treatment, have been widely investigated but still have their limitations. There is currently no specific method to solve all the problems encountered in heavy oil transportation and exploitation.

Microwave heating effect arises from the interaction between the electric field and the charged particles in the material. If the charged particles are bound within regions of the material, i.e. in liquid or solid substances, the electric field will cause them to move until opposing forces balance the electric force. High frequency microwaves are responsible for collisions amongst the moving molecules due to the induced dipole moments produced by the applied electric fields. This in turn is responsible for heating [8]. In general, the higher the induced polarity, the greater the influence of microwaves. 
Therefore, microwave heating possesses the advantages of selective heating and volumetric heating.

Due to the specific microwave heating mechanism, more and more applications have been employed to the oil industry, including petroleum exploration and transport. Research proves that microwave heating can irreversibly reduce the viscosity of heavy oils [9-11]. This technology is efficient, clean and generates no pollution. Microwave energy was first used in the 1950s for petroleum exploitation [12]. In 1977, Bosisi et al [13] carried out the first experiment of microwave extraction of asphaltene from sand shale, they found that the average molecular weight of asphaltene after microwave heating is lower than that of conventional heating. Moreover, small amount of $\mathrm{CO}_{2}, \mathrm{CO}, \mathrm{H}_{2}, \mathrm{CH}_{4}, \mathrm{C}_{2} \mathrm{H}_{6}$ gases were produced. Bosisi et al [13] also found thermal cracking of asphaltene occurred under microwave irradiation, which could be attributed to the thermal effect of microwave.

Researchers have examined the technology of microwave assisted exploitation. Sresty et al [14] found that $35 \%$ oil can be obtained from oil sand after microwave treatment. Pizarro et al [15] conducted a low frequency electrical heating field trial in the RIO Panan oil field in Brazil, and showed that the output can be increased from $1.2 \mathrm{bbl} / \mathrm{d}$ to $10 \mathrm{bbl} / \mathrm{d}$ after 70 days at a heating power of $20 \mathrm{~kW}$. Wall [16] proved by experiment that the exploitation of high pour point crude oil is more economical through microwave technology, the produced oil obtained lower water content relative to the oil generated from conventional heating.

Recent studies show that the combination of electromagnetic (EM) heating and gas injection can efficiently enhance the oil recovery, a recovery of $45 \%$ was achieved using the combination of electromagnetic heating and gas injection, however only $24 \%$ and $20 \%$ oil can be obtained by applying electromagnetic heating and gas injection respectively [17]. The electromagnetic heating reduces the viscosity of oil, whilst the injected gas sweeps the heated oil away towards the production well, thus providing improved recovery rates [17]. Combining solvent injection with EM heating has also proved to further reduce the energy intensity of the process $[18,19]$. The research of $\mathrm{Hu}$ et al [18] shows that combined EM heating and solvent assisted gravity drainage could effectively enhance heavy oil recovery up to $83.59 \%$ by using alternate EM heating and n-octane injection. With EM heating alone, the recovery is only $12.37 \%$.

There are two theories on the mechanism of microwave viscosity reduction of heavy oil: thermal effect and non-thermal effect [10,11,19-23]. For the thermal effect, microwave selective heating makes the temperature distribution within the treated material non-uniform, the temperature in the polar 
component (resin and asphaltene) area is much higher making these materials decompose into small molecule materials, thus reduced the viscosity $[10,11,19,20,22]$. The theory of non-thermal effect states that microwave heating could reduce the molecule's activation energy and then induce cracking at low temperatures [21-23].

Although many studies have shown that microwave radiation may reduce the viscosity of crude oil irreversibly, the principles are still unclear, and there is a lack of research at the molecular level to analyze the reduction mechanism. The aim of this work was to investigate the effect of microwave treatment on the viscosity, SARA content, and heteroatom compounds of crude oil samples from Sudan, Liaohe (China) and Venezuela. In order to examine the mechanism of viscosity reduction by microwave irradiation at a molecular level, SARA fractionation and ESI-FT ICR MS analysis were carried out.

\section{Materials and methods}

\subsection{Materials}

All solvents and reagents used in saturate, aromatic, resin and asphaltene (SARA) fractionation are of analytical grade without any further purification. The solvents used in ESI FT-ICR MS are of HPLC grade and used as received. The crude oil samples used in this study were obtained from Sudan, Venezuela and Liaohe (China). The characteristics of the crude oil samples are listed in Table 1.

\subsection{Microwave-assisted viscosity reduction}

Experiments were carried out using a $3 \mathrm{~kW}$ single mode microwave cavity system, operated at 2.45 $\mathrm{GHz}$ (Figure 1). Fifty milliliters of crude oil sample was loaded in an $80 \mathrm{ml}$ poly-tetrafluoroethylene (PTFE) reactor. The reactor was then sealed and heated by a continuous microwave irradiation at $2 \mathrm{~kW}$ for $5 \mathrm{~min}$. The viscosity of the treated sample was measured using Brookfield DV-II+ Pro Viscometer after it was cooled down to room temperature.

\subsection{Hydrocarbon group types analysis}

The crude oil and microwave treated samples were subjected to a standard SARA fractionation test according to the American Society Test and Materials (ASTM D4124-09). The sample was first separated into alkane-insoluble asphaltenes and an alkane-soluble fraction by n-heptane. The n-heptane soluble fraction was then absorbed onto a column filled with calcined alumina and further separated into 
saturates, aromatics and resins factions using a series of elution solvents, i.e. n-heptane, toluene and a mixture of toluene and ethanol $(1: 1 \mathrm{v} / \mathrm{v})$. The solvents in each effluent were then removed by vacuum rotary evaporation.

2.4 Fourier transform ion cyclotron resonance mass spectrometer (FT-ICR MS) analysis

FT-ICR MS is currently the highest resolution mass spectrometer available. The heteroatom compounds in the crude oil cannot be detected under general conditions, but can be accurately identified with this high-resolution mass spectrometer [24].

Electrospray ionization (ESI) enables the identification of heteroatom compounds, down to trace quantities. The combination of ESI with FT-ICR and MS provides important means for the analysis of non-hydrocarbon compounds in heavy oil.

Crude oil and microwave treated samples were analyzed using a Bruker Apex Ultra FT-ICR MS equipped with a 9.4 T actively shielded superconducting magnet. Sample solutions were prepared at 0.2 $\mathrm{mg} \cdot \mathrm{ml}^{-1}$ in $1: 3(\mathrm{v} / \mathrm{v})$ toluene/methanol for the positive ion mode and at the same concentration in formic acid for the negative ion mode. The parameters of the negative and positive ion modes are listed in Table 2.

\section{Results and Discussions}

\subsection{Effect of microwave radiation on viscosity}

The effects of microwave radiation on the viscosity of three different crude oil samples were investigated by applying continuous microwave irradiation to the oil samples at $2 \mathrm{~kW}$ for $5 \mathrm{~min}$. The viscosity of the crude oil and microwave-treated samples are plotted in Figure 2. The viscosity of Sudan and Venezuela crudes reduced by $43.8 \%$ at $30^{\circ} \mathrm{C}$ and $28.9 \%$ at $85^{\circ} \mathrm{C}$, respectively after heating. Both changes in the viscosity were permanent. However, Liaohe crude exhibited an opposite response to microwave heating, the viscosity increased by $42.7 \%$ at $40^{\circ} \mathrm{C}$. Most studies of crude oil microwave heating in literature reported a reduction in the viscosity after microwave irradiation. This was reportedly due to the heat generated by microwave-induced molecular movements [25,26]. However no explanation was given for the irreversible change in the viscosity, or in some cases the increase in the viscosity after microwave heating. Therefore, in order to investigate the mechanism of viscosity reduction by microwave irradiation at a molecular level, SARA fractionation and ESI-FT ICR MS analysis were conducted. 


\subsection{Influence of SARA fractions on crude oils' viscosity}

The SARA analysis was conducted on all the three crude oil samples before and after microwave irradiation. The results are listed in Table 3. The measurement standard error for the SARA fractions is $\pm 0.63 \%$. By comparing the viscosity and SARA compositional data of 200 crude oil samples, Malkin et al [27] found a general trend that an increase in asphaltenes, resins, and aromatics leads to an increase in viscosity, while an increase in saturates results in a drop in viscosity. This finding was also applicable to the three crude oils in this work. The order of the viscosities of the three samples followed the trend of their saturates and asphaltenes concentrations. Venezuela crude had the highest viscosity with the highest asphaltenes concentration and lowest saturates concentration, while the Sudan crude had the lowest viscosity with the lowest asphaltenes concentration and highest saturates concentration. However, this general trend does not explain the mechanisms of viscosity changes after the microwave treatment. The saturates concentration of the microwave treated Sudan crude decreased by $4.4 \%$, while its viscosity reduced after the microwave treatment. The saturates in Liaohe crude increased by $4.1 \%$ but its viscosity also increased after microwave treatment. There is no significant difference for SARA contents before and after microwave treatment of Venezuela crude. A $7.0 \%$ increase of the aromatics concentration in Sudan crude oil and a $4.1 \%$ decrease of the one in Liaohe crude oil were also observed. The trend of the viscosity changes against the changes of the aromatics concentration was also contradictory to Malkin's finding. Therefore, the change of SARA fractions alone cannot be used to explain the viscosity changes.

The ratio of resins to asphaltenes is another useful parameter, which has been widely used as a key indicator of asphaltene stability. Higher ratio of resins to asphaltenes leads to higher asphaltene stability [28]. This is based on the micelle theory of the physical structure of crude oils. In this theory asphaltenes are the centers of micelles formed by adsorption of resin compounds on the surface or into the interiors of the asphaltene particles. The greater molecular weight substances and those with the most pronounced aromatic nature are situated closest to the nucleus and are surrounded by lighter constituents of lesser aromatic nature. The transition of the intermicellar phase is gradual and almost continuous [29,30]. The presence of resin compounds is essential for the dispersibility of the asphaltene constituents. As shown in Table 3, the ratio of resins to asphaltenes for the Sudan and Venezuela crudes increased. This could lead to a higher stability of asphaltenes in the crudes, therefore, lower viscosity. In contrast, the ratio of resins to asphaltenes for the Liaohe crude reduced, resulting in the higher viscosity. This shows that the microwave irradiation might affect the micelle structure formed by resins and asphaltenes, and lead to a 
change in the viscosity.

\subsection{Influence of microwave irradiation on the heteroatom compounds}

The presence of small amount of heteroatom compounds can remarkably affect the crude oil's properties, including its viscosity [31]. It is necessary to analyze the heteroatom compounds to better understand the effect of microwave irradiation at the molecular level. Quantitative analysis was carried out on all oil samples before and after the microwave irradiation using ESI FT-ICR MS analysis. The standard sample $-\mathrm{C}_{18} \mathrm{D}_{35} \mathrm{HO}_{2}$ with the concentration of $10^{-5} \mathrm{~mol} / \mathrm{l}$ was used to investigate the changes of molecular compositions within crude oils (Figure 3).

In order to make a more intuitive comparison of the composition changes after microwave treatment, the heteroatom compounds were classified in the positive and negative ion modes. Figures 4 and 5 show the distribution of heteroatom classes in the crude oils before and after the treatment. The percent relative abundance is the summed abundance for each class divided by the abundance of all species. Seven and four chemically distinct classes were detected in the samples from the negative ion and positive ion ESI FT-ICR MS, respectively. Comparing the three crudes, it was found that Venezuela crude had the highest amount of N1S1 compounds in both the negative and positive ions ESI FT-ICR mass spectra, which corresponds to the high sulfur content reported in Table 1. The class of N1 compounds was the most abundant heteroatom class in Sudan and Venezuela crudes, while the O2 class was the most abundant heteroatom class in Liaohe crude. The relative abundance of $\mathrm{O} 2$ class has been associated with the acid content in crude oils [32], which could explain the high acid value of the Liaohe crude (Table 1).

The contents of $\mathrm{N} 1$ compounds decreased and $\mathrm{O} 2$ compounds increased after microwave treatment for both Sudan and Liaohe crudes based on the negative ion ESI FT-ICR MS analysis, whereas for the Venezuela crude, the trend was opposite. From the positive ion ESI FT-ICR MS analysis, the relative abundance N1 compounds for Sudan and Venezuela crudes were lower after microwave irradiation, while for Liaohe crude, the value increased. These findings indicate that even though the viscosity is the result of the combined effects of various factors, basic nitrogen compounds within the crude oils may have a great influence on the viscosity.

In order to analyze the chemical composition changes, double bond equivalents (DBE) of N1 and $\mathrm{O} 2$ compounds were studied before and after microwave treatment (Figures. 6 and 7). DBE is defined as 
the number of rings plus double bonds involving carbon for a petrochemical composition, $\mathrm{C}_{\mathrm{c}} \mathrm{H}_{\mathrm{h}} \mathrm{N}_{\mathrm{n}} \mathrm{O}_{\mathrm{o}} \mathrm{S}_{\mathrm{s}}$ :

$$
\mathrm{DBE}=\mathrm{c}-\frac{\mathrm{h}}{2}+\frac{\mathrm{n}}{2}+1
$$

From Figures 6 and 7, minimal changes can be found after microwave treatment, in order to analyze the chemical composition changes in detail, the unsaturated N1 and $\mathrm{O} 2$ compounds of the crude oil samples were grouped by their carbon numbers based on the data in Figures 6 and 7. These two classes were chosen as they were the most abundant classes in the crude oil samples. The results are plotted in Figures 8 and 9 with the difference before and after the microwave treatment marked in red.

As shown in Figure 8, after microwave irradiation, the abundance of the N1 compounds with higher carbon numbers for all three crudes increased above the carbon number. The abundance of the N1 compounds in the Liaohe crude reduced in the carbon number range of 20-30, and the abundance of this class increased in the carbon number range of 45-65 after the microwave irradiation. This observation indicates that polymerization could occur during the microwave treatment.

Figure 9 shows the abundance of the $\mathrm{O} 2$ compounds in the crude oils before and after microwave irradiation. The abundance of the $\mathrm{O} 2$ compounds in the carbon number range of 20-40 in Sudan crude decreased significantly and some smaller compounds were detected in the range of 10-15. This suggests that cracking occurred during the microwave treatment for Sudan crude. This might explain why the viscosity of Sudan crude reduced after microwave irradiation. The abundance of the $\mathrm{O} 2$ compounds of Venezuela crude also reduced, leading to lower viscosity. However, for Liaohe crude, the abundance of the $\mathrm{O} 2$ compounds with the high carbon number increased. This indicates polymerization could be the dominate reaction for Liaohe crude during the microwave treatment. It also resulted in higher viscosity of Liaohe crude after microwave irradiation.

\subsection{Mechanism of viscosity changes due to microwave irradiation}

The results obtained demonstrate that the constituents in the crude oils are the key factors in determining its viscosity, especially the heteroatom compounds. Under microwave irradiation, the polar substances such as $\mathrm{S}, \mathrm{N}$ and $\mathrm{O}$ containing materials absorb more microwave energy, thus may induce some reactions. Polymerization could occur in a crude oil with more $\mathrm{O} 2$ compounds (high acid value) under microwave irradiation, resulting in increased viscosity. In other cases, cracking may occur due to the microwave selective heating and result in a reduction of the viscosity. Since asphaltenes and resins 
are composed of highly poly-aromatic species with alkyl side chains and heteroatoms (S, N, and O) and metals (especially Ni and V), making them the most polar and heaviest petroleum fraction. These polar materials will induce intermolecular interactions such as acid-base, hydrogen bonding, coordination, and $\pi-\pi$ stacking interactions [33]. Microwave irradiation can also affect the interaction between substances in the crude oils and change the micelle structure within them [34-37]. It could lead to stability changes of the asphaltenes/resins micelle structure and thus the viscosity of the crude oils.

Since the composition and physical structure of crude oils are excessively complex, viscosity is not induced by one single component. It is a result of the combination of various components and their interactions. The effect of microwave irradiation on the interactions between the components in crude oils is complex and requires further research. Future work will focus on studying the interactions between different substances from both experiments and simulations methods.

\section{Conclusion}

In this work, the effect of microwave treatment on the viscosity, SARA content, and heteroatom compounds of crude oil samples from Sudan, Liaohe (China) and Venezuela was investigated. Microwave irradiation highly affected the viscosity of crude oil. The increase or decrease of viscosity depends on the composition of the crude oil, especially the heteroatom compounds. The viscosity of Sudan and Venezuela crudes reduced while that of Liaohe crude increased after microwave irradiation. SARA fractionation results showed that microwave irradiation affect the stability of the asphaltenes/resins micelle. An increase or decrease in the ratio of resins to asphaltenes after microwave treatment leads to a decrease or increase of crude oil viscosity, respectively. The ESI FT-ICR MS results, demonstrated that a high proportion of $\mathrm{O} 2$ compounds would cause polymerization and result in an increase of the viscosity after the microwave irradiation. In other cases, cracking might occur due to the microwave heating.

\section{Acknowledgement}

This work was supported by the National Science Foundation of China under Grant Nos. 21476258 and 21176256 for funding this project.

\section{References}

[1] R. Martínez-Palou, M. de L. Mosqueira, B. Zapata-Rendón, E. Mar-Juárez, C. Bernal-Huicochea, J. de la C. 
Clavel-López, J. Aburto, Transportation of heavy and extra-heavy crude oil by pipeline: a review, J. Petrol. Sci. Eng. 75 (2011) 274-282.

[2] M.T. Ghannam, S.W. Hasan, B. Abu-Jdayil, N. Esmail, Rheological properties of heavy \& light crude oil mixtures for improving flowability, J. Petrol. Sci. Eng. 81 (2012) 122-128.

[3] J.F.P. Bassane, C.M.S. Sad, D.M.C. Neto, F.D. Santos, M. Silva, F.C. Tozzi, P.R. Filgueiras, E.V.R.de Castro, W. Romão, M.F.P. Santos, J.O.R. da Silva, V. Lacerda Jr., Study of the effect of temperature and gas condensate addition on the viscosity of heavy oils, J. Petrol. Sci. Eng. 142 (2016) 163-169.

[4] S.N. Ashrafizadeh, E. Motaee, V. Hoshyargar, Emulsification of heavy crude oil in water by natural surfactants, J. Petrol. Sci. Eng. 86-87 (2012) 137-143.

[5] Y.P. Gao, K.W. Li, New models for calculating the viscosity of mixed oil, Fuel. 95 (2012; 431-437.

[6] J.G. Speight, Petroleum asphaltenes - Part 1: asphaltenes, resins and the structure of petroleum, Oil Gas Sci. Technol. 59 (2004) 467-477.

[7] N. Shigemoto, R.S. Al-Maamari, B.Y. Jibril, A. Hirayama, A study of the effect of gas condensate on the viscosity and storage stabilityon Omani heavy crude oil, Energ. Fuel. 20 (2006) 2504-2508.

[8] S.W. Hasan, M.T. Ghannam, N. Esmail, Heavy crude oil viscosity reduction and rheology for pipeline transportation, Fuel. 89 (2010) 1095-1100.

[9] R. Tao, X. Xu, Reducing the viscosity of crude oil by pulsed electric or magnetic field, Energ. Ful. 20 (2006) 2046-2051.

[10] Y. Wang, The study of the mechanism on the viscosity reduction of the heavy oil radiated by the microwave [dissertation], Insititute of Electrics. Chinese Academy of Sciences, 2002. Chinese.

[11] H.Y. Jiang, Study on the effect of microwave on high viscosity and high pour point crude[dissertation], Southwest Petroleum University, 2004, Chinese.

[12] H.W. Ritchey, Radiation heating, United States patent US 2757738. Aug. 7. 1956.

[13] R.G. Bosisio, J.L. Cambon, C. Chavarie, D. Klvana, Exprimental result on the hesting of athabasca tar sand samples with microwave power, J. Micro. Power 12 (1977) 301-307.

[14] G.C. Sresty, H. Dev, R.H. Snow, J.E. Bridges, Recovery of bitumen from tar sand deposits with the radio frequency process, SPE Reservoir Engineering 1 (1986) 85-94.

[15] J.O.S. Pizarro, O.V. Trevisan, Electrical heating of oil reservoirs: numerical simulation and field test results, J. Petrol. Technol. 42 (1990) 1320-1326.

[16] E.T. Wall, Method and apparatus for recovering carbon products from oil shale, United States patent US 4376034. Mar.8. 1983.

[17] K.N. Jha, A. Chakma, Heavy-oil recovery from thin pay zones by electromagnetic heating, Energ. Source. 21 (1999) 63-73. 
[18] L. Hu, H.A. Li, T. Babadagli, M. Ahmadloo, Experimental investigation of combined electromagnetic heating and solvent-assisted gravity drainage for heavy oil recovery, J. Petrol. Sci. Eng. 154 (2017) 589-601.

[19] A. Bera, T. Babadagli, Status of electromagnetic heating for enhanced heavy oil/bitumen recovery and future prospects: A review, Appl. Energ. 151 (2015) 206-226.

[20] L. Kovaleva, A. Davletbaev, T. Babadagli, Z. Stepanova, Effects of electrical and radio-frequency electromagnetic heating on the mass-transfer process during miscible injection for heavy-oil recovery, Energ. Fuel, 25 (2013) 482-486.

[21] B. Ren, A study of microwave a thermal effect on heavy oil [dissertation], Xi'an Shiyou University, 1999, Chinese.

[22] Q.H. Zhang, The Study of the viscosity reduction of the crude oil radiated by the microwave [dissertation], Xi'an Shiyou University, 2014, Chinese.

[23] A.J. Qi, Experimental study on microwave frenquency effect on the rheological property of heavy oil [dissertation], Xi'an Shiyou University, 2015, Chinese.

[24] Q. Shi, D.J Hou, K.H. Chung, C.M. Xu, S.Q. Zhao, Y.H. Zhang, Characterization of heteroatom compounds in a crude oil and its saturates, aromatics, resins, and asphaltenes (SARA) and non-basic nitrogen fractions analyzed by negative-ion electrospray ionization Fourier transform ion cyclotron resonance mass spectrometry, Energ. Fuel. 24 (2010) 2545-2553.

[25] V. Peraser, S.L. Patil, S. Khataniar, A.Y. Dandekar, S.V. Sonwalkar. Evaluation of electromagnetic heating for heavy oil recovery from Alaskan reservoirs, SPE-154123-MS, SPE Western Regional Meeting, Bakersfield, California, USA, 21-23 March, 2012. https://doi.org/10.2118/154123-MS.

[26] A.K. Jha, N. Joshi, A. Singh, Applicability and assessment of microwave assisted gravity drainage (MWAGD) applications in mehsana heavy oil field, India, SPE Heavy Oil Conference and Exhibition, Kuwait City, Kuwait, 12-14 December, 2011. https://doi.org/10.2118/149591-MS.

[27] A.Y. Malkin, G. Rodionova, S. Simon, S.O. Ilyin, M.P. Arinina, V.G. Kulichikhin, J. Sjoblom, Some compositional viscosity correlations for crude oils from Russia and Norway, Energ. Fuel. 30 (2016) 9322-9328.

[28] A. Hammami, K.A. Ferworn, J.A. Nighswander, S. Over, E. Stange, Asphaltenic crude oil characterization: an experimental investigation of the effect of resins on the stability of asphaltenes, Petrol. Sci. Technol. 16 (1998) 227-249.

[29] J.G. Speight, The chemistry and technology of petreoleum, 4th ed, CRC Press, Boca Raton, 2007.

[30] J.P. Pfeiffer, and R.N. Saal, Asphaltic bitumen as colloid system, Phys. Chem. 44 (1940) 139-149.

[31] R.G. Santos, W. Loh, A.C. Bannwart, O.V. Trevisan, An overview of heavy oil properties and its recovery and transportation methods, Braz. J. Chem. Eng. 31 (2014) 571-590.

[32] B.G. Vaz, P.V. Abdelnur, W.F.C. Rocha, A.O. Gomes, R.C.L. Pereira, Predictive petroleomics: measurement of 
the total acid number by electrospray fourier transform mass spectrometry and chemometric analysis, Energ. Fuel. 27 (2013) 1873-1880.

[33] Z.T. Chen, L.Z. Zhang, S.Q. Zhao, Q. Shi, C.M..Xu, Molecular structure and association behavior of petroleum asphaltene, Springer Internatinoal Publishing, Switzerland, 2015.

[34] A.A. Antony, C.P. Smyth, Microwave absorption and molecular structure in liquids. LIII. Hydrogen bonding and dielectric properties in chloroform mixtures, J. Am. Chem. Soc. 86 (1964) 152-156.

[35] J. Crossley, Microwave dielectric relaxation in some hydrogen-bonded solutions, Adv. Mol. Relaxn. Intn. Processes. 14 (1979) 115-120.

[36] T. Vishwam, V.R.K. Murthy, Microwave dielectric relaxation studies of hydrogen bonded polar binary mixtures of isobutanol and aniline, J. Mol. Struct. 1035 (2013) 46-53.

[37] F.H. Liu, W.Y. Tian, X.Q. Yang, G.Z. Jia, Hydrogen-bonding and dielectric response of N,N-dimethylacetamide aqueous solutions under E/M fields using molecular dynamics, J. Mol. Liq. 197 (2014) 100-105. 


\section{Figure Captions}

Figure 1. Microwave treatment system

Figure 2. Viscosity of the crude oil samples before and after the microwave treatment ( $2 \mathrm{~kW}$ for 5 minutes)

Figure 3. Negative ion ESI FT-ICR mass spectra for Sudan crude oil before and after microwave irradiation (left) and the segment enlarge mass spectra (right) (a: crude oil; b: crude oil after microwave)

Figure 4. Relative abundance of heteroatom classes for the three crude oils before and after microwave irradiation derived from negative ion ESI FT-ICR MS (a. Sudan crude, b. Liaohe crude, c. Venezuela crude)

Figure 5. Relative abundance of heteroatom classes for the three crude oils before and after microwave irradiation derived from positive ion ESI FT-ICR MS (a. Sudan crude, b. Liaohe crude, c. Venezuela crude)

Figure 6. DBE distribution of N1 compounds within Sudan, Liaohe and Venezuela crude oils before and after microwave treatment

Figure 7. DBE distribution of $\mathrm{O} 2$ compounds within Sudan, Liaohe and Venezuela crude oils before and after microwave treatment

Figure 8. Changes of N1 compounds in crude oils before and after microwave treatment (a. Sudan crude, b. Liaohe crude, c. Venezuela crude)

Figure 9. Changes of $\mathrm{O} 2$ compounds in the crude oils before and after microwave treatment (a. Sudan crude, b. Liaohe crude, c. Venezuela crude)

\section{Table Captions}

Table 1 Key physical properties of the crude oil samples

Table 2 Operating parameters of the negative and positive ion ESI source

Table 3 The changes of the SARA fractions of the crude oil samples after microwave irradiation (a. crude oil; b. oil sample after microwave irradiation) 
Table 1 Key physical properties of the crude oil samples

\begin{tabular}{cccc}
\hline Item & Sudan & Liaohe & Venezuela \\
\hline API $^{\circ}$ & 22.3 & 15.2 & 16.1 \\
Density $\left(20{ }^{\circ} \mathrm{C}\right), \mathrm{kg} \cdot \mathrm{m}^{-3}$ & 0.92 & 0.95 & 0.96 \\
Oil classification & $\begin{array}{c}\text { Middle-Naphthene } \\
\text { biddle based }\end{array}$ & & \\
baphthene based \\
Acid value, $\mathrm{mg} \mathrm{KOH} \cdot \mathrm{g}^{-1}$ & 2.13 & 4.70 & 1.24 \\
Viscosity $\left(40^{\circ} \mathrm{C}, \mathrm{cP}\right)$ & 202.1 & 1112.2 & $1546.4\left(85^{\circ} \mathrm{C}\right)$ \\
Carbon residue, $\%$ & 7.53 & 9.00 & 11.13 \\
Sulfur, $\%$ & 0.75 & 0.34 & 2.49 \\
Nitrogen, $\%$ & 0.51 & 0.38 & 0.46 \\
Nickel, $\mu \mathrm{g} \cdot \mathrm{g}^{-1}$ & 54 & 46.8 & 79 \\
Vanadium, $\mu \mathrm{g} \cdot \mathrm{g}^{-1}$ & 0.9 & 1.54 & 396 \\
\hline
\end{tabular}

Table 2 Operating parameters of the negative and positive ion ESI source

\begin{tabular}{lll}
\hline Parameter & Negative ion mode & Positive ion mode \\
\hline Polarization voltage & $4500 \mathrm{~V}$ & $4600 \mathrm{~V}$ \\
Inlet capillary voltage & $4100 \mathrm{~V}$ & $4100 \mathrm{~V}$ \\
Outlet capillary voltage & $-320 \mathrm{~V}$ & $320 \mathrm{~V}$ \\
Ion accumulation time of hexapole & $0.01 \mathrm{~s}$ & $0.001 \mathrm{~s}$ \\
Ion source RF voltage of hexapole & $300 \mathrm{Vp}-\mathrm{p}$ & $700 \mathrm{Vp}-\mathrm{p}$ \\
Quadrupole optimization mass & $\mathrm{Q} 1 \mathrm{~m} / \mathrm{z} 250$ & $\mathrm{Q} 1 \mathrm{~m} / \mathrm{z} 200$ \\
Collision cell argon gas flow rate & $0.3 \mathrm{~L} \cdot \mathrm{S}^{-1}$ & $0.3 \mathrm{~L} \cdot \mathrm{S}^{-1}$ \\
Collision energy & $1.5 \mathrm{~V}$ & $-1.5 \mathrm{~V}$ \\
Collision cell accumulation time & $0.01 \mathrm{~s}$ & $0.001 \mathrm{~s}$ \\
Sampled mass range & $154 \sim 800 \mathrm{Da}$ & $154 \sim 800 \mathrm{Da}$ \\
Infusion flow rate & $180 \mu \mathrm{l} \cdot \mathrm{h}^{-1}$ & $180 \mu \mathrm{l} \cdot \mathrm{h}^{-1}$ \\
\hline
\end{tabular}


Table 3. The changes of the SARA fractions of the crude oil samples after microwave irradiation (a. crude oil; b. oil sample after microwave irradiation)*

\begin{tabular}{|c|c|c|c|c|c|c|c|c|c|c|c|}
\hline \multirow[b]{2}{*}{ Sample } & & \multicolumn{2}{|c|}{ Saturates (S) } & \multicolumn{2}{|c|}{ Aromatics (Ar) } & \multicolumn{2}{|c|}{ Resins (R) } & \multicolumn{2}{|c|}{ Asphaltenes (As) } & \multicolumn{2}{|c|}{$\mathrm{R} / \mathrm{As}$} \\
\hline & & $\begin{array}{l}\text { Fraction } \\
(\%)\end{array}$ & $\begin{array}{l}\text { Change } \\
(\%)\end{array}$ & $\begin{array}{l}\text { Fraction } \\
(\%)\end{array}$ & $\begin{array}{l}\text { Change } \\
(\%)\end{array}$ & $\begin{array}{l}\text { Fraction } \\
(\%)\end{array}$ & $\begin{array}{l}\text { Change } \\
(\%)\end{array}$ & $\begin{array}{l}\text { Fraction } \\
(\%)\end{array}$ & $\begin{array}{l}\text { Change } \\
(\%)\end{array}$ & Ratio & $\begin{array}{l}\text { Change } \\
(\%)\end{array}$ \\
\hline \multirow{2}{*}{ Sudan } & $\mathrm{a}$ & 45.76 & - & 24.79 & - & 24.45 & - & 5.00 & - & 4.89 & - \\
\hline & $\mathrm{b}$ & 43.77 & $-4.4 \%$ & 26.53 & $7.0 \%$ & 24.90 & $1.8 \%$ & 4.81 & $-3.9 \%$ & 5.18 & $6.0 \%$ \\
\hline \multirow{2}{*}{ Liaohe } & $\mathrm{a}$ & 40.98 & - & 28.79 & - & 21.25 & - & 5.5 & - & 3.86 & . \\
\hline & $\mathrm{b}$ & 42.67 & $4.1 \%$ & 27.6 & $-4.1 \%$ & 20.8 & $-2.1 \%$ & 5.44 & $-1.1 \%$ & 3.82 & $-1.0 \%$ \\
\hline \multirow{2}{*}{ Venezuela } & $\mathrm{a}$ & 20.31 & - & 38.81 & - & 29.72 & - & 10.94 & - & 2.72 & 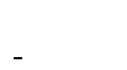 \\
\hline & $\mathrm{b}$ & 20.11 & $-1.0 \%$ & 39.49 & $1.8 \%$ & 29.78 & $0.2 \%$ & 10.86 & $-0.7 \%$ & 2.74 & $0.9 \%$ \\
\hline
\end{tabular}

* The measurement standard error for the SARA fractions is $\pm 0.63 \%$. The SARA total fraction is normalized to $100 \%$.

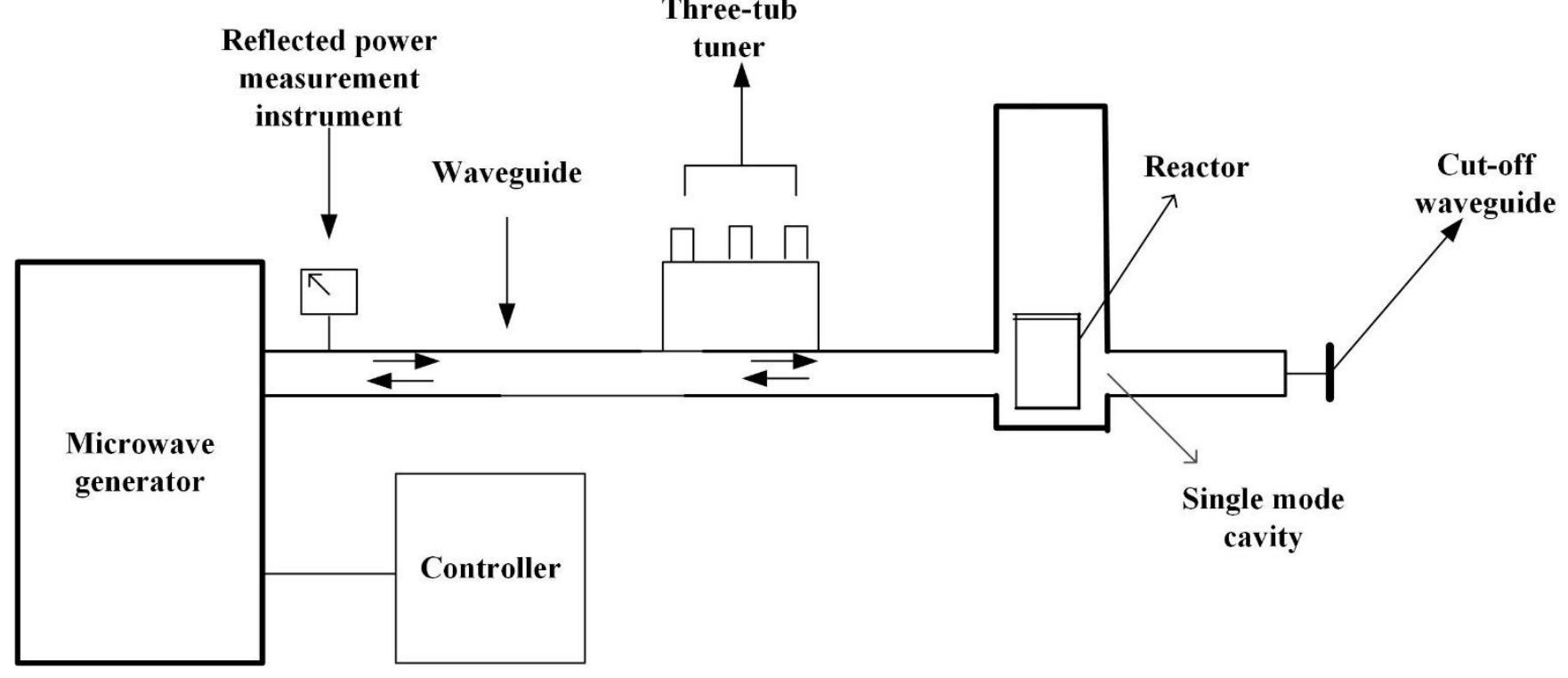

Figure 1. Microwave treatment system 


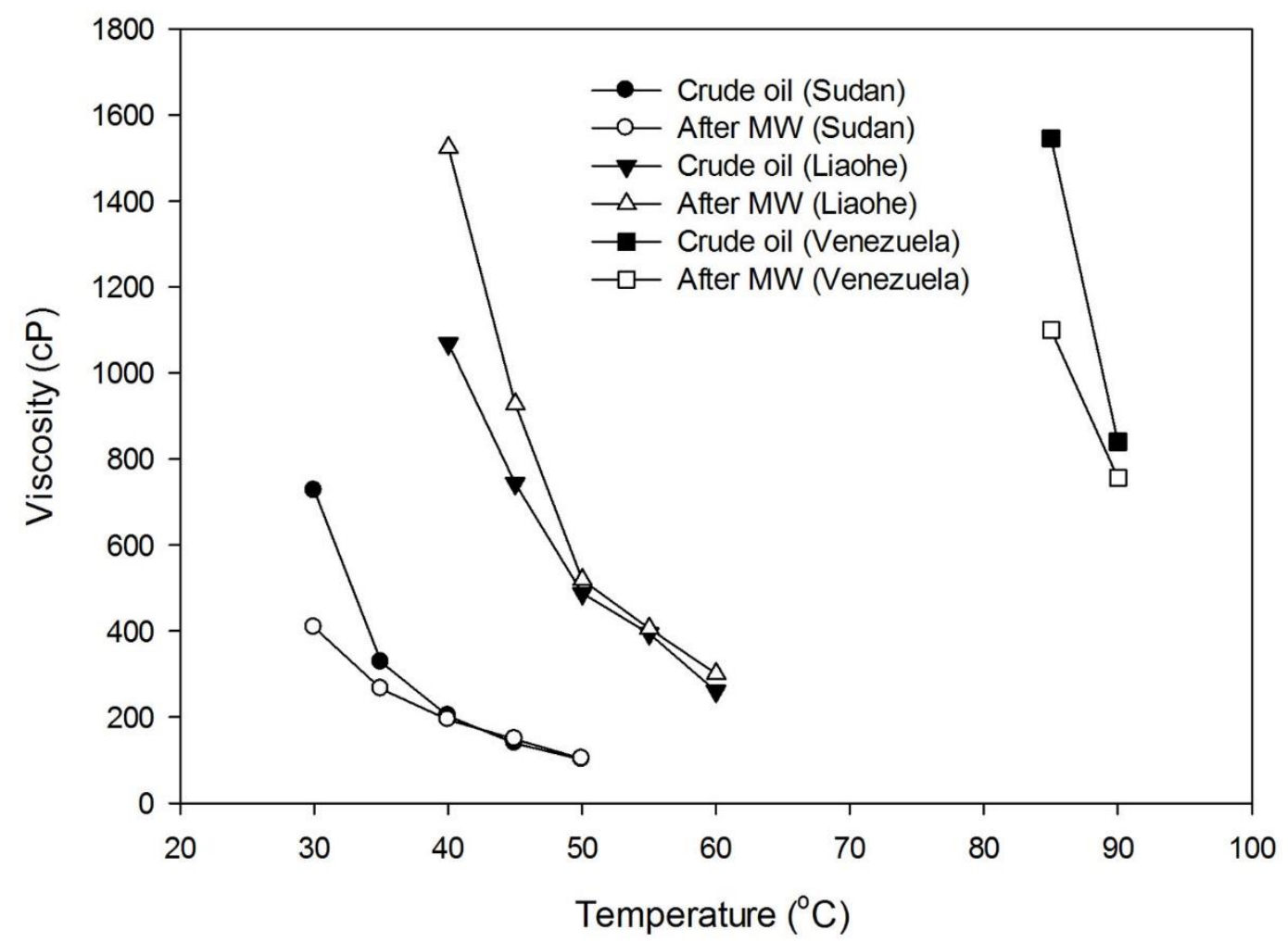

Figure 2. Viscosity of the crude oil samples before and after the microwave treatment ( $2 \mathrm{~kW}$ for 5 minutes)

Figure 3. Negative ion ESI FT-ICR mass spectra for Sudan crude oil before and after microwave irradiation (left) and the segment enlarge mass spectra (right) (a: crude oil; b: crude oil after microwave)

Figure 4. Relative abundance of heteroatom classes for the three crude oils before and after microwave irradiation derived from negative ion ESI FT-ICR MS (a. Sudan crude, b. Liaohe crude, c. Venezuela crude)

Figure 5. Relative abundance of heteroatom classes for the three crude oils before and after microwave irradiation derived from positive ion ESI FT-ICR MS (a. Sudan crude, b. Liaohe crude, c. Venezuela crude)

Figure 6. DBE distribution of N1 compounds within Sudan, Liaohe and Venezuela crude oils before and after microwave treatment

Figure 7. DBE distribution of $\mathrm{O} 2$ compounds within Sudan, Liaohe and Venezuela crude oils before and after microwave treatment

Figure 8. Changes of N1 compounds in crude oils before and after microwave treatment (a. Sudan crude, b. Liaohe crude, c. Venezuela crude)

Figure 9. Changes of $\mathrm{O} 2$ compounds in the crude oils before and after microwave treatment (a. Sudan crude, b. Liaohe crude, c. Venezuela crude) 


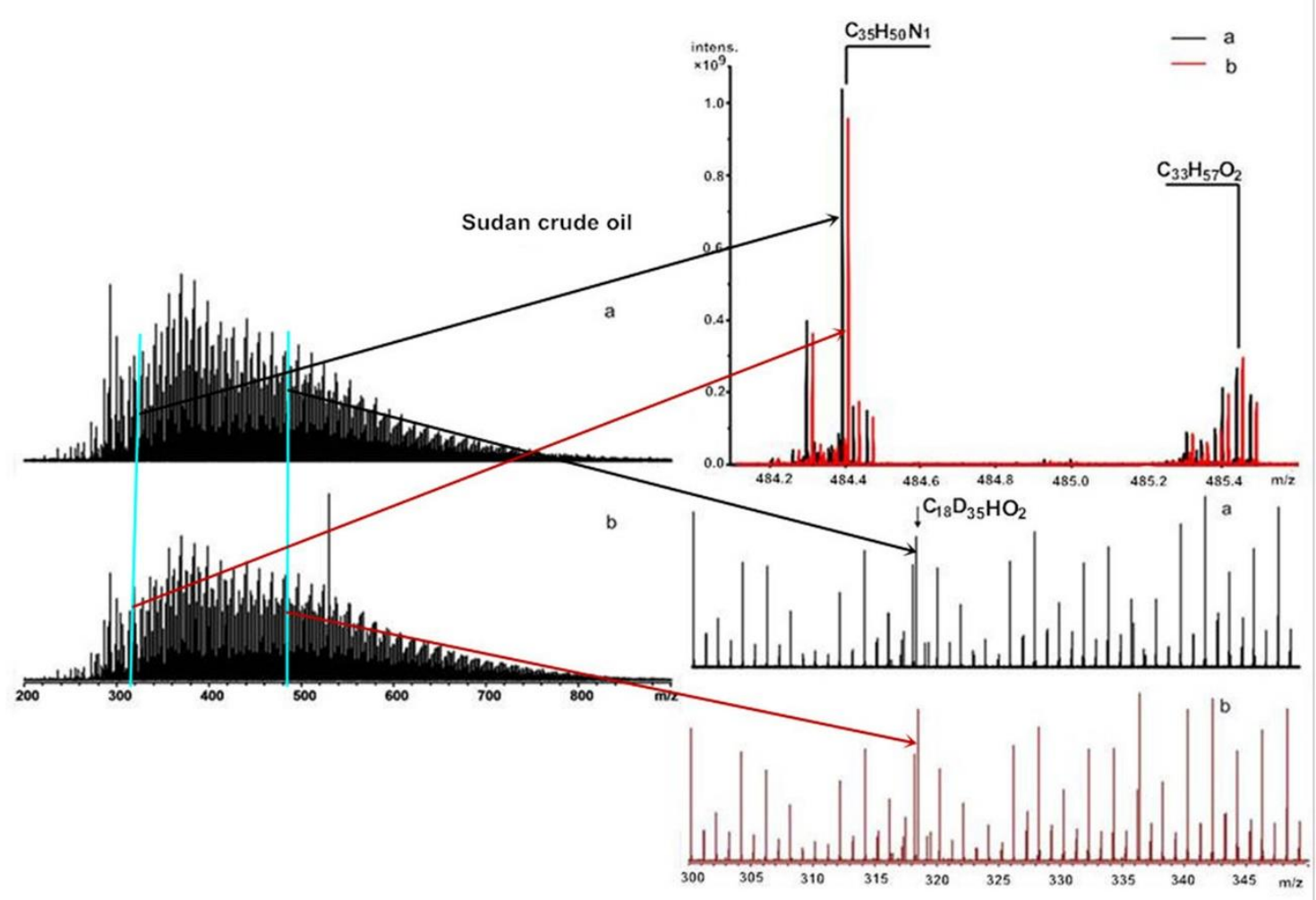

Figure 3. Negative ion ESI FT-ICR mass spectra for Sudan crude oil before and after microwave irradiation (left) and the segment enlarge mass spectra (right) (a: crude oil; b: crude oil after microwave)
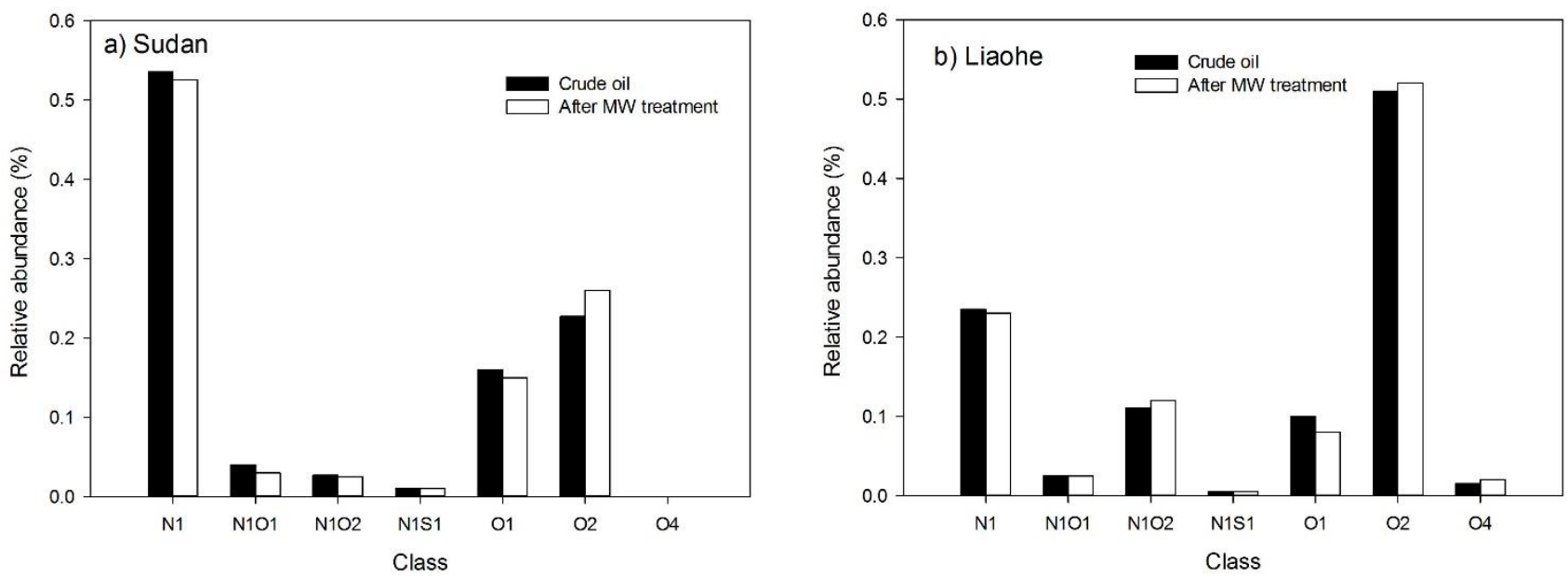


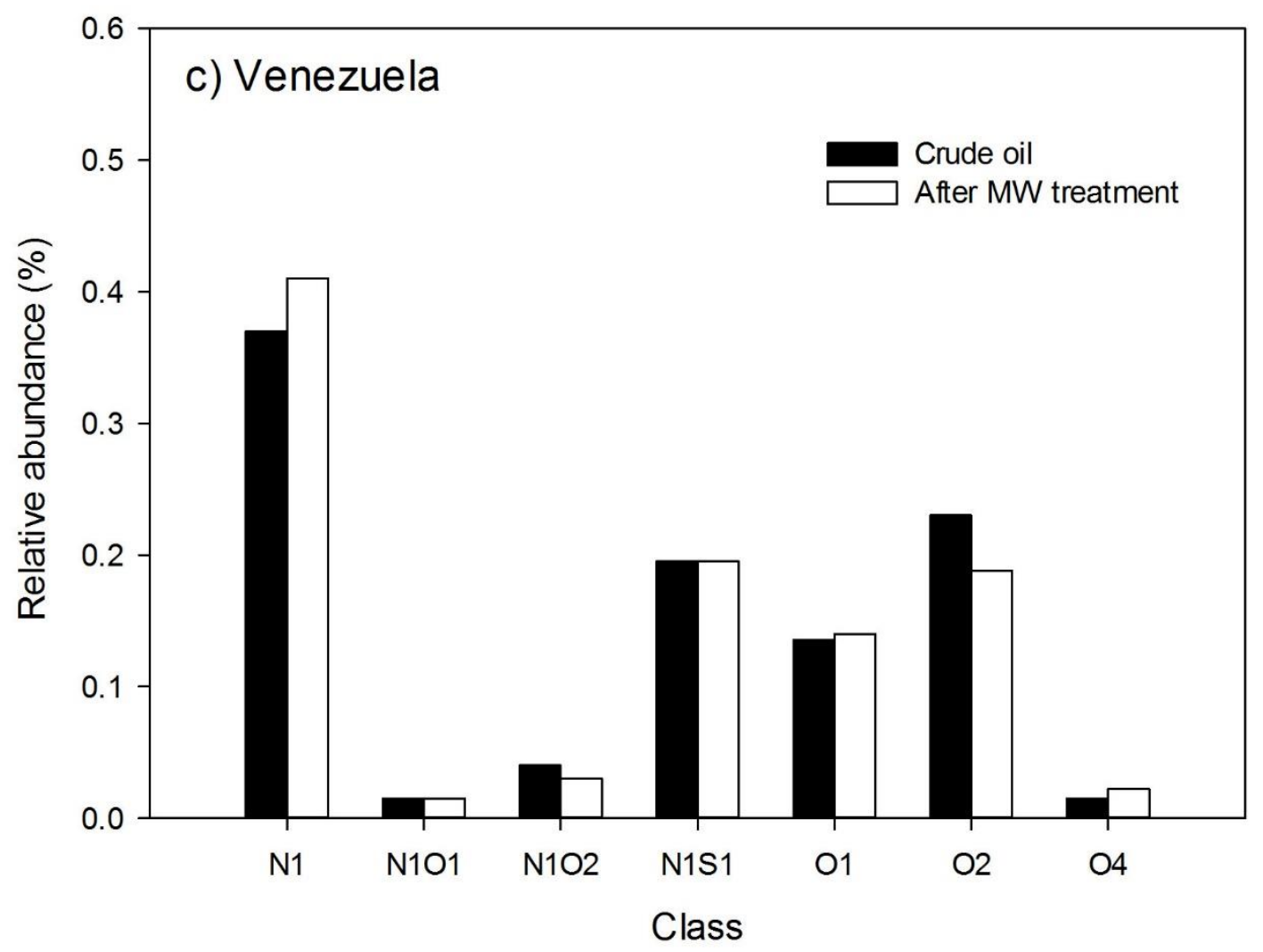

Figure 4. Relative abundance of heteroatom classes for the three crude oils before and after microwave irradiation derived from negative ion ESI FT-ICR MS (a. Sudan crude, b. Liaohe crude, c. Venezuela crude)
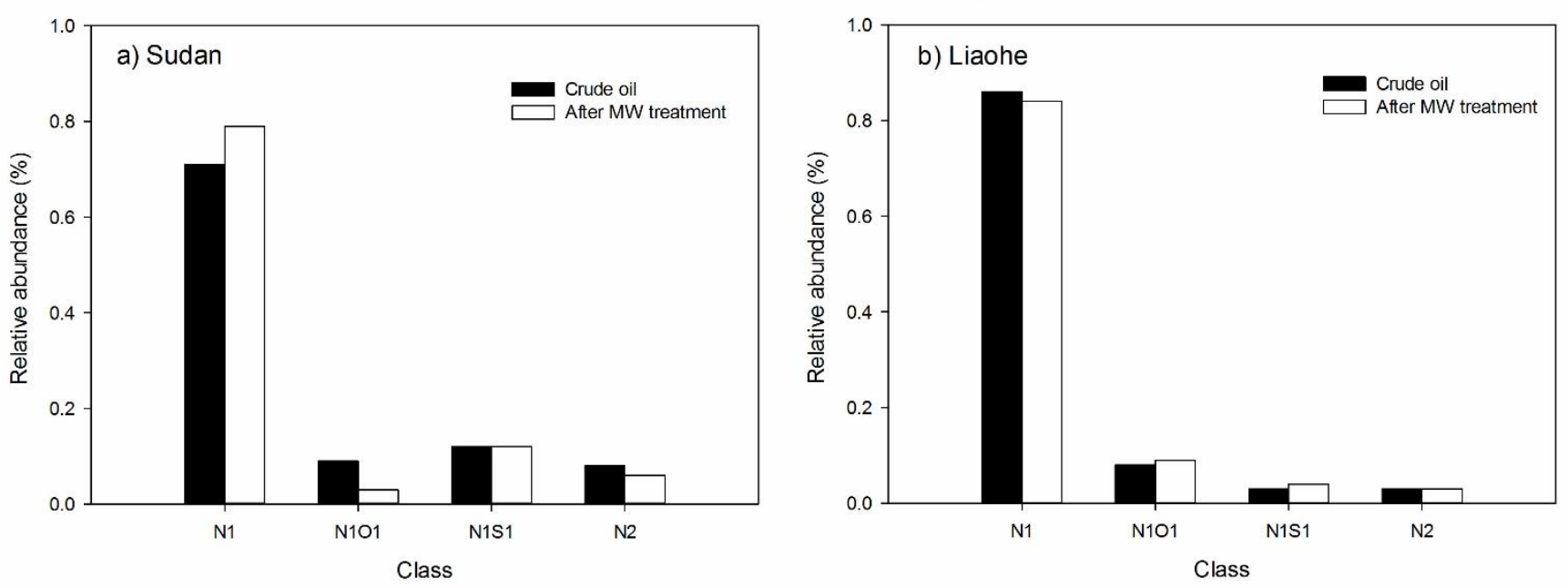


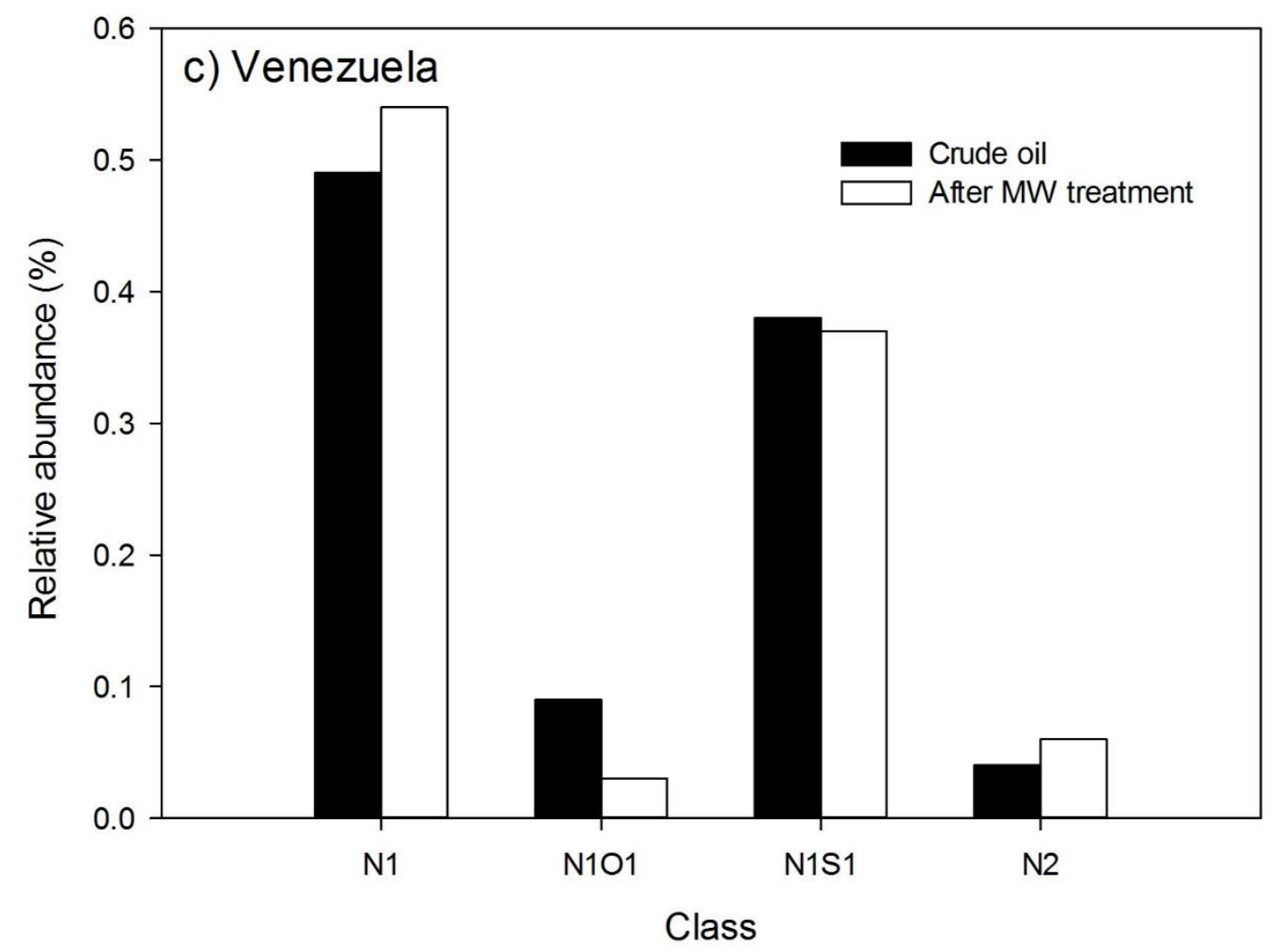

Figure 5. Relative abundance of heteroatom classes for the three crude oils before and after microwave irradiation derived from positive ion ESI FT-ICR MS (a. Sudan crude, b. Liaohe crude, c. Venezuela crude)
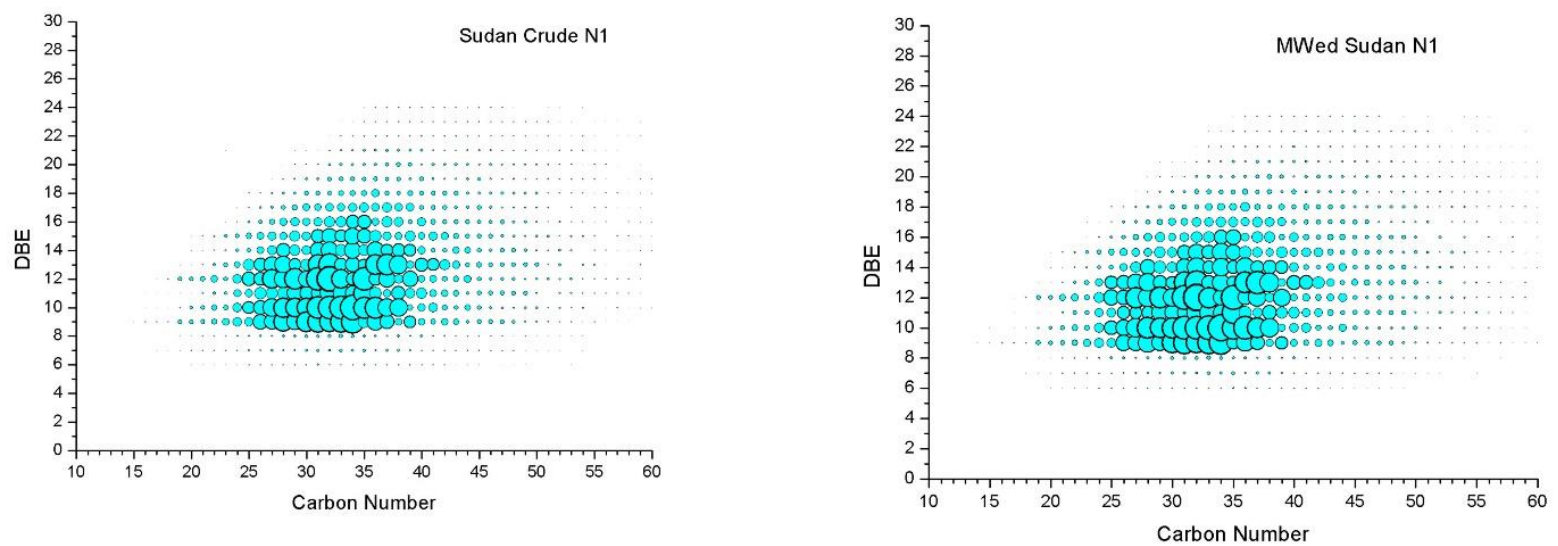

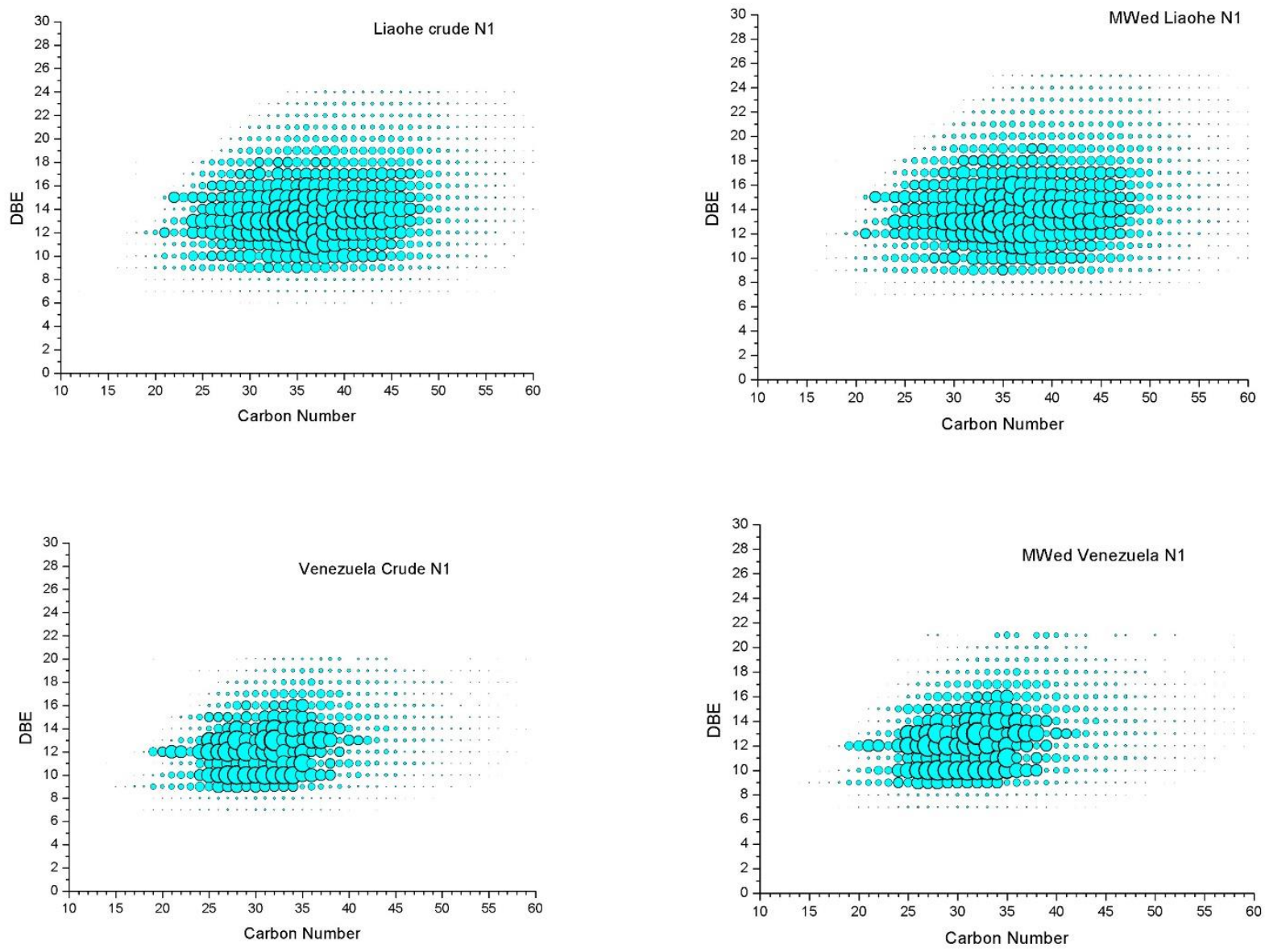

Figure 6. DBE distribution of N1 compounds within Sudan, Liaohe and Venezuela crude oils before and after microwave treatment
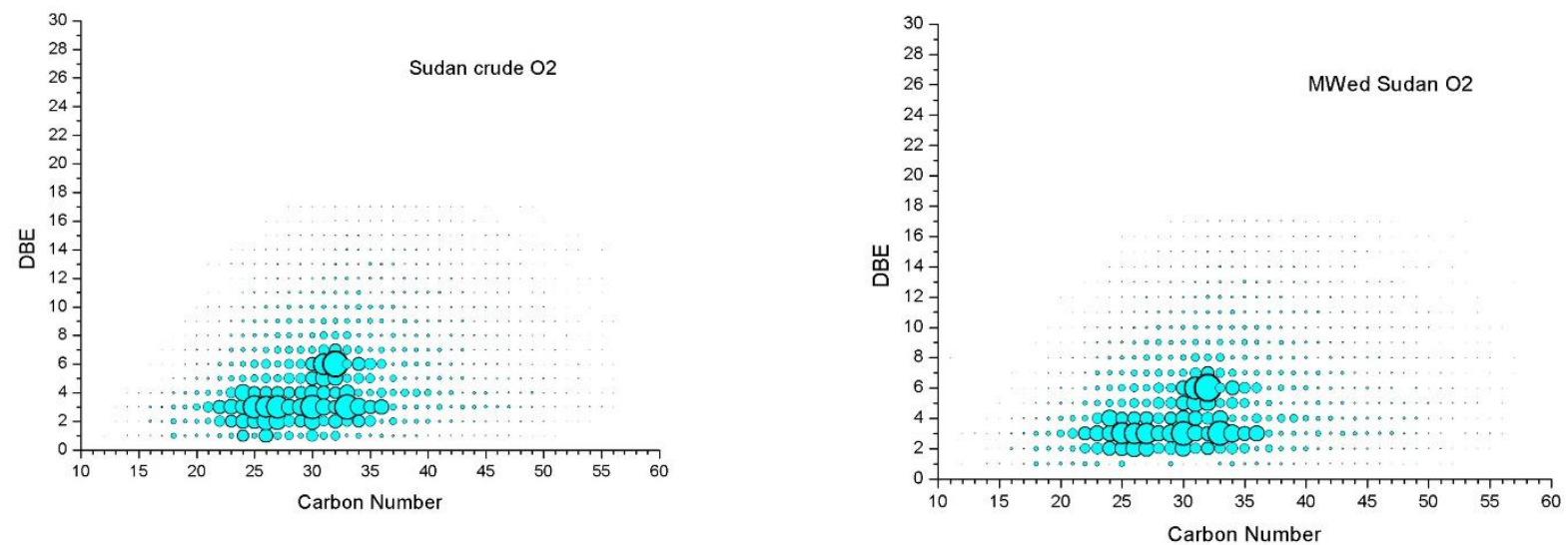

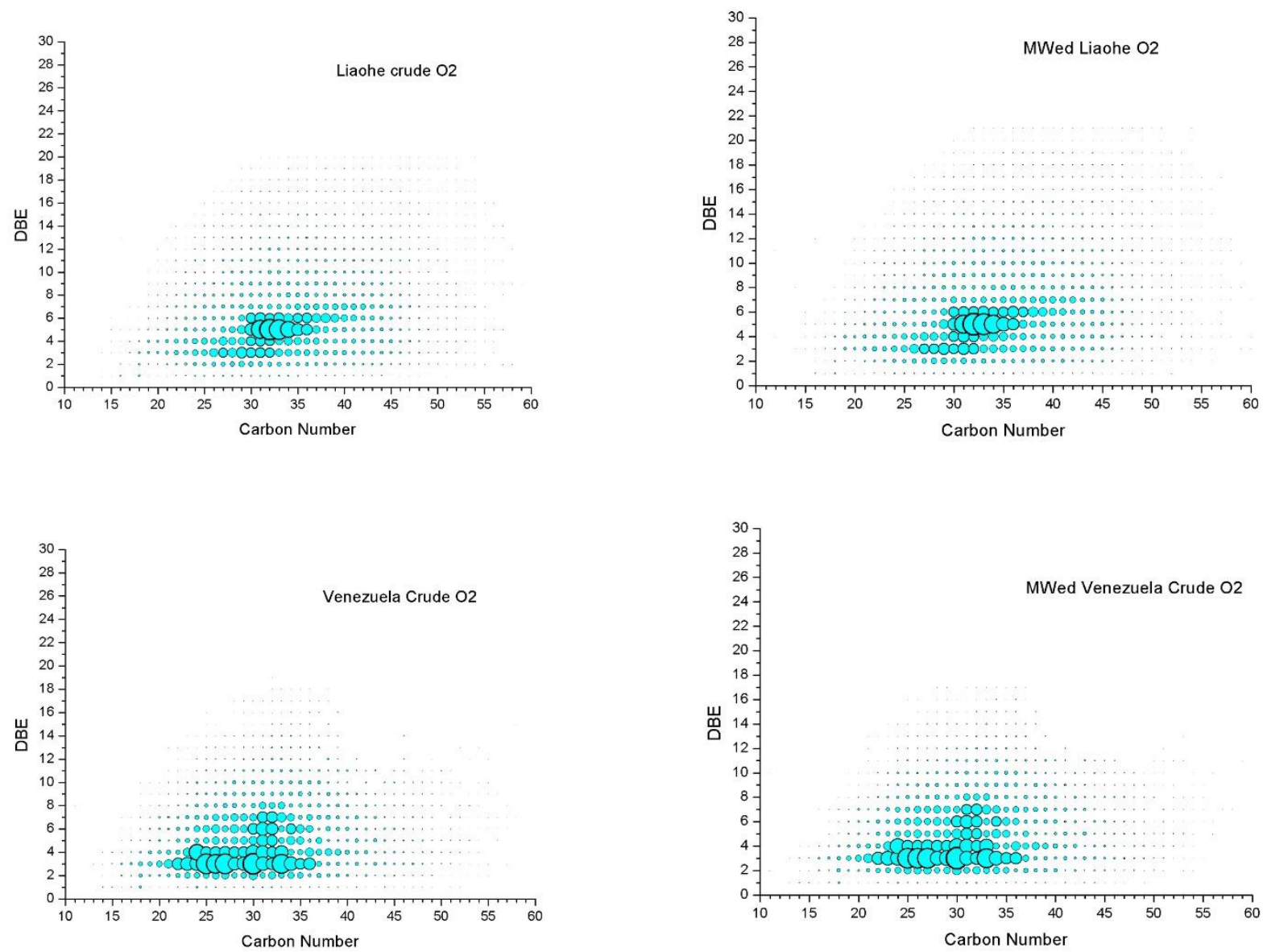

Figure 7. DBE distribution of $\mathrm{O} 2$ compounds within Sudan, Liaohe and Venezuela crude oils before and after microwave treatment
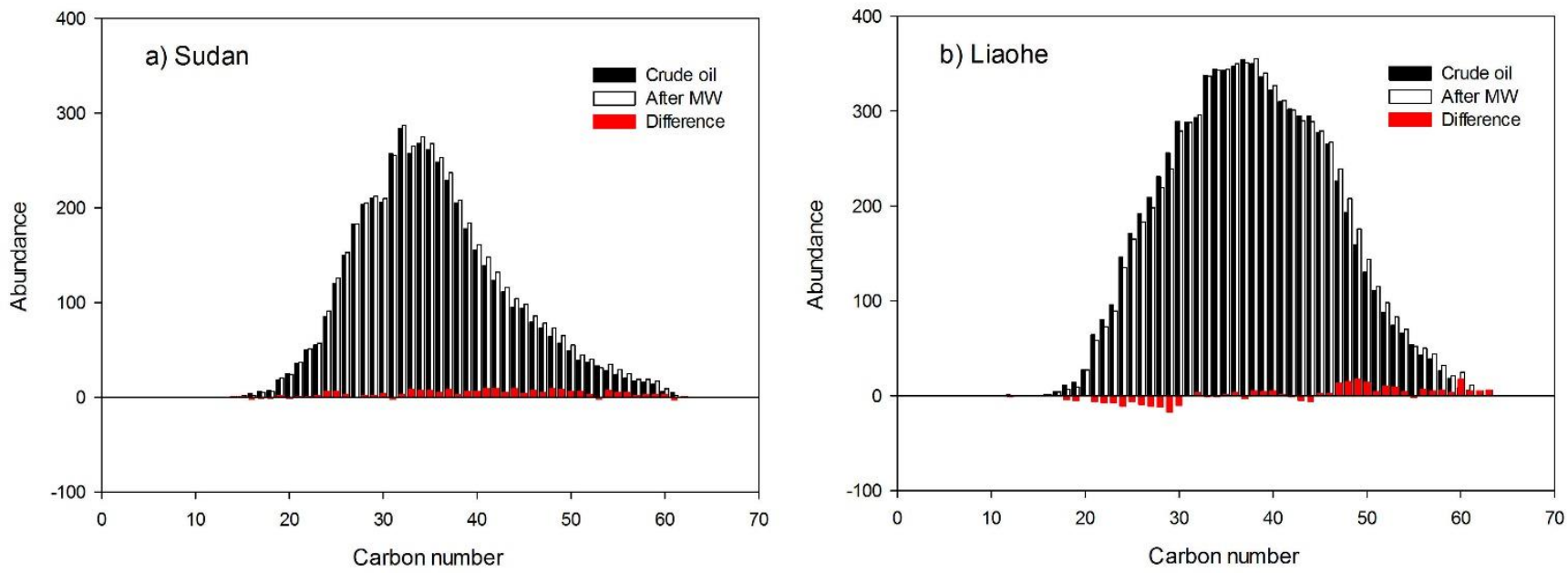


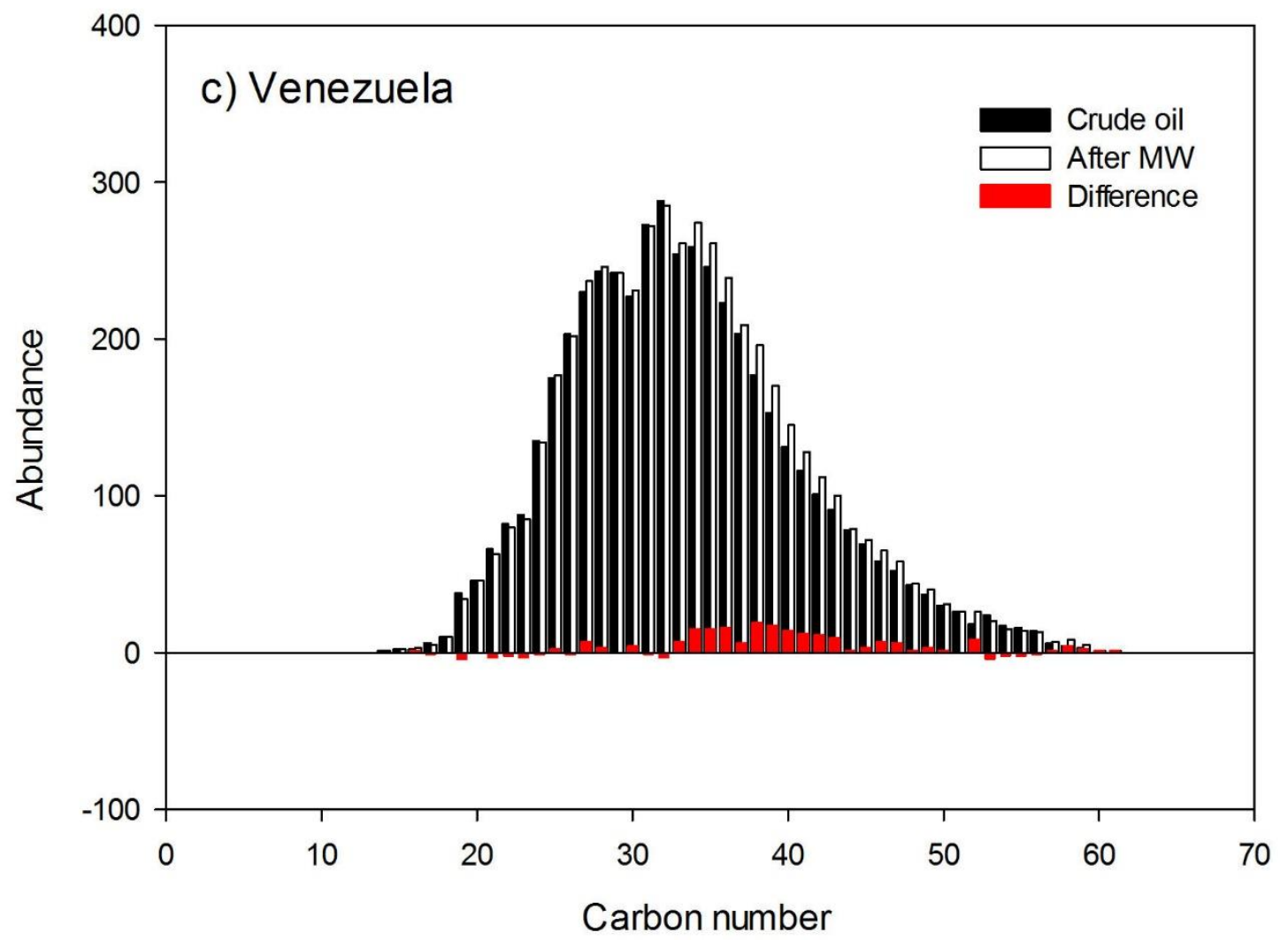

Figure 8. Changes of N1 compounds in crude oils before and after microwave treatment (a. Sudan crude, b. Liaohe crude, c. Venezuela crude)
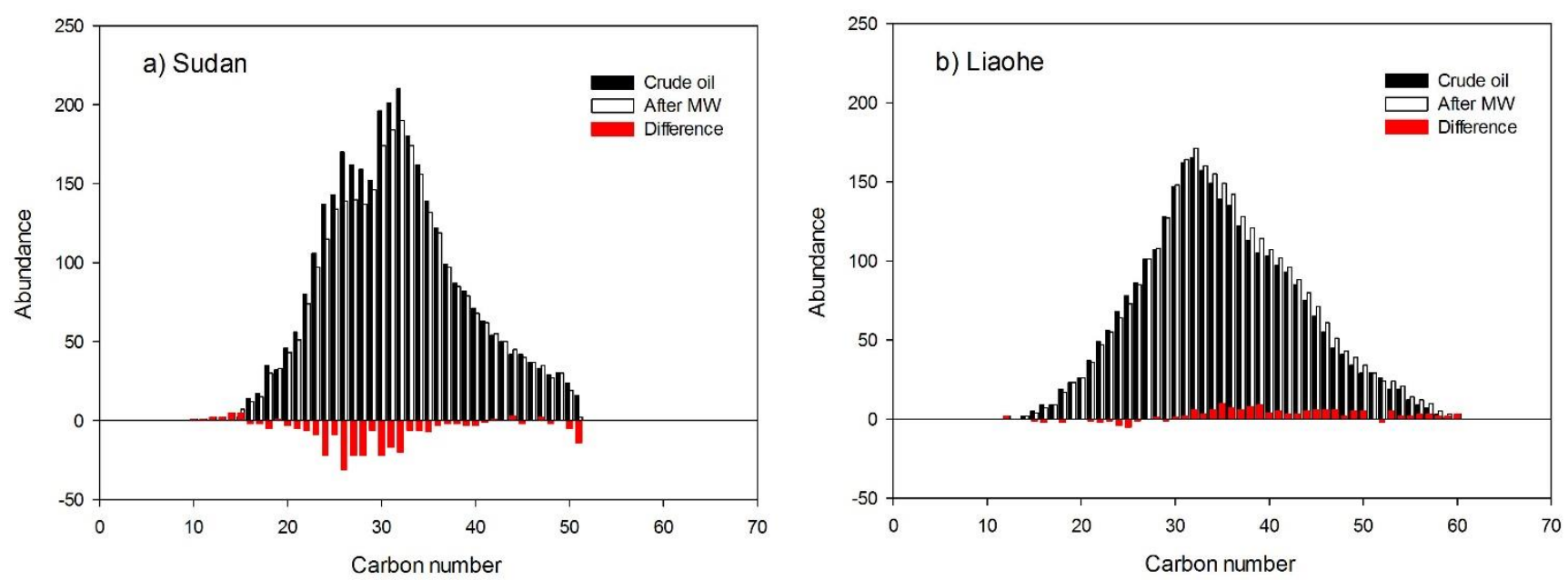


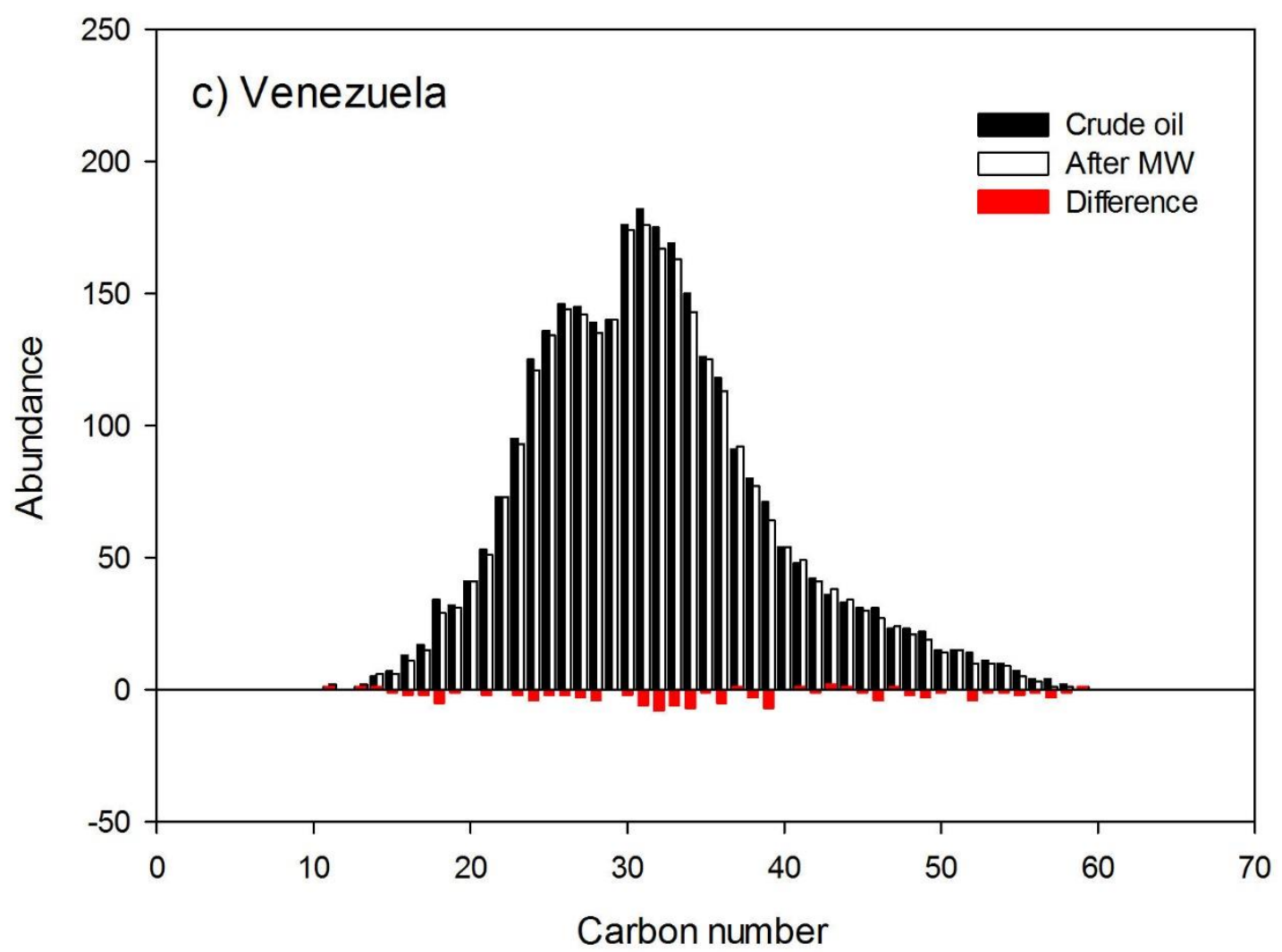

Figure 9. Changes of $\mathrm{O} 2$ compounds in the crude oils before and after microwave treatment (a. Sudan crude, b. Liaohe crude, c. Venezuela crude) 